\title{
Macau Squares: Discerning the Triadic Sign Model of Built-Heritage
}

\author{
Mark Hansley Yang Chua
}

check for

updates

Citation: Chua, M.H.Y. Macau Squares: Discerning the Triadic Sign Model of Built-Heritage. Sustainability 2021, 13, 7024. https://doi.org/ $10.3390 /$ su13137024

Academic Editor: Marek Nowacki

Received: 30 April 2021

Accepted: 19 June 2021

Published: 22 June 2021

Publisher's Note: MDPI stays neutral with regard to jurisdictional claims in published maps and institutional affiliations.

Copyright: (C) 2021 by the author. Licensee MDPI, Basel, Switzerland. This article is an open access article distributed under the terms and conditions of the Creative Commons Attribution (CC BY) license (https:// creativecommons.org/licenses/by/ $4.0 /)$.
Department of Real Estate and Construction, Faculty of Architecture, University of Hong Kong, Hong Kong; mhychua@connect.hku.hk

Abstract: Despite an objectivist vision by many heritage conservation bodies, the extant literature mostly dwells on the value of heritage as something subjective and arbitrary. Semiotically treating built-heritage as a Peircian triadic sign, instead of a dyadic sign, could reconcile this apparent dichotomy. Some squares of Macau]'s Historic Centre are taken as case study. Using a Coasian perspective, this paper argues how the meaning-delimiting consequences of a triadic semiotic framework allow for a lower transaction cost in valuation and eventually a more sustainable conservation. This has been confirmed by an expert decision in designating the relatively new squares as heritage protected areas.

Keywords: triadic sign; heritage conservation; square; Macau; transaction cost

\section{Preamble}

"It should be possible in a given scene to determine wherein its special characters and beauty consists: what is essential and what may be changed. There must be, in a word, some sort of assessment of values; it is not enough to say which landscape or piece of country is precious and which of ordinary value, but in what consists the special quality for which it is valuable" [1] p. 196: italics the author's.

The above quote from Sir Patrick Abercrombie, a founder of the Royal Institute of Planners, illuminates the importance of uniqueness in heritage assessment as a type of value assessment in land use.

\section{Introduction}

Every assessment of values has an underlying epistemological foundation. This specific way of thinking and its consequent ways of doing affect the Coasian transaction cost, or institution cost—as Cheung [2] called it once (which, in reality, is never zero). Built heritage is no exception.

The value of built-heritage is taken by many as something that changes over time and across cultures. Yet, various international heritage institutions clamour for a universal, beyond culture sense of heritage value. Heritage value can then be seen to be subjective on one hand and yet transcend the subject on the other. This dichotomy poses an important threat against sustainably conserving built-heritage. Obviously, the way the assessment and evaluation of heritage values are carried out affects the conservation, land use, and tourism of a site. In order to lessen the negative effects of this, what has become formalised as a "heritage impact assessment" (HIA) process recommends that the compositions of the assessment teams be experts and stakeholders from different fields and backgrounds [3]. Patiwael, Groote \& Vanclay [4] argued that one of the issues with the International Council on Monuments and Sites (ICOMOS) HIA guidelines is the unclear understanding of the nature of heritage values to different practitioners and experts. Among many examples of conflicts, Cheung [5], for instance, described the saga here in Asia of how four groups of stakeholders (including the Tourism Board) had different interpretations in planning and managing the conservation works of an old Chinese village in Hong Kong. Attempts have 
also been made to reconcile this, for example, Boccardi [6] proposes a fact-versus-value (objective-versus-subjective attribution) paradigm in operationalising the authenticity of a heritage site.

Contributing to the theorisation of heritage value, this paper proposes to frame builtheritage as a semiotic structure as it traditionally has been-but in the triadic sense, not the dyadic sense. Built-heritage generally acts to "evoke remembrance of something"normally something of worth in the past. In fact, etymologically, this is how the famous philosopher Cicero (see $[7,8]$ ) defined a monument around 2000 years ago: quae faciunt alicuius rei recordationem. On top of a building's former or current function and even its present aesthetic merits, a building or a group of buildings or a certain space also functions as a sign pointing to some event or person of worth in the past for someone. A monument, as a form of built-heritage, taken in this sense is essentially a sign. Nevertheless, two widely used semiotic models describe the reality of signs: the dyadic model and the triadic model. Which model is applied makes a whole world of difference for built-heritage conservation projects.

The next subsection briefly expounds on the existing problem related to the objectivistsubjectivist dichotomy apparent in the heritage field. It is followed by a theoretical exposition of the difference between the two semiotic models and how the triadic model reconciles the apparent dichotomy.

The proposed seed framework is then applied and tested against a real example, the squares in Macau's Historical Centre, as a case study. This application to Macau is timely because Macau's outstanding universal value "bears a unique testimony to the first and longest-lasting encounter between the West and China, from the 16th to the 20th centuries" [9] p.61. In turn, the square of Macau's Historic Centre was added to the World Heritage List as a protected area together with the inscribed monument buildings they surround.

Using a Coasian perspective in the discussion section, this paper argues that the meaning-delimiting consequences of a triadic semiotic framework facilitate valuation (lowering the transaction cost) and eventually a more sustainable conservation. This has been confirmed by international recognition of the squares as World Heritage protected areas. The paper then concludes by recapping the concepts and framework with some other applications.

\subsection{Objectivist-Subjectivist Dichotomy as a Threat to Sustainability}

Heritage value is an important factor to consider in sustainable conservation. Decisions to deem an edifice/assembly to be built-heritage are normally dependent on this valuation. The importance of value in built-heritage conservation is generally acknowledged. For instance, the authoritative Nara Document of Authenticity affirms that "conservation of cultural heritage ... is rooted in the values attributed to the heritage" [10] para. 9. The commentary found in an earlier version of the China ICOMOS also recognises that "the fundamental significance of a heritage site resides in its inherent values" [11] p. 71.

Nevertheless, leading organisations in heritage conservation generally define value or value-related concepts along two different streams. One stream, the Burra Charter states that "cultural significance may change over time and with use" [12] art. 1.2 Notes Similarly, the Nara Document of Authenticity states that "all judgements about values attributed to cultural properties ... may differ from culture to culture, and even within the same culture" [10] no. 11 In fact, the document drafted for its 20th anniversary, called the Nara+20 [13], defined authenticity as a "culturally contingent quality." The Council of Europe's Framework Convention on the Value of Cultural Heritage for Society takes "cultural heritage ... as a reflection and expression of their constantly evolving values, beliefs, knowledge and traditions" [14] art. 2a The "Conservation Principle" in the glossary of Historic England [15] defines value as "an aspect of the worth or importance attached by people to qualities of places, categorised as aesthetic, evidential, communal or historical value". 
In the other stream, there seems to be common acceptance that value is "... so exceptional it is as to transcend national boundaries and to be of common importance for present and future generations of all humanity" [16] no. 49. Recognising the site's heritage values requires discerning its transcendence as "a continuous and open-ended process that deepens as society develops and its scientific and cultural awareness increases" [11] p. 71.

In line with these two streams, Zancheti and Jokilehto distinguished two perspectives of value: there is the "objective-utilitarian" view, which regards value as "the quality of a thing that makes it useful or desirable", and the more subjective or "relativistic" view, where value is defined as "relative social attribution of qualities of things" [17] p. 40. The former view acknowledges intrinsic values embedded in the object-built-heritage in this case-and the latter considers them to be projections of a person and/or society's perspectives-a construct or category [18]. Similarly, Davies [19] described attitudes toward built-heritage to range from an attitude that values the past and the art-relic for itself to an attitude that is indifferent to the past and sees art as a mere social construct. Throsby [20], in his review of cultural values theories in relation to economic value, also compared two notions of value: one absolute and the other more relativist. Similarly, Avrami, Mason, and de la Torre of the Getty Conservation Institute acknowledged that "a postmodernist tendency to reduce cultural heritage to simply a social construction runs up against the widely held understanding that heritage is in fact imbued with some universal, intrinsic qualities" [18] p. 7: italics the author's.

Without directly defining values as such, other authors lean towards perceiving values in line with the more subjective notion. For instance, Arizpe [21] noted that the worth of an object depends on the values people confer on it, which she exemplified by using the effects of globalisation: how people's perceptions about specific heritage sites around the world are affected through the internet. Heritage value is frequently described as attributed, not intrinsic, and mutable [22]. Pushed to its extreme consequences, it can even be used to support the notion that our ideas and language are not a reflection of reality but are the cause of it [23].

While some large international bodies seem to have pressed for a more transcendental understanding of value-not without reason-to safeguard their conservation efforts and lessen conflicts, a good number of authors and groups seem to associate it more with the subjective behaviour observed in valuing heritage. The two seemingly opposed perspectives of the one reality appear to produce a subjectivist-objectivist dichotomy. To reconcile these two extreme identities of one reality, the authors propose to use the extra-linguistic triadic model of signs rather than the commonly applied dyadic one.

The introductory lines from the planning guru Sir Patrick Abercrombie summarise the contention quite curtly. When it comes to project valuation, knowing what is essential and what is changeable is of utmost relevance, yet it also demands an appropriate mind frame that can cater to both. Where the baseline seems hazy, the transaction cost in carrying out works for conservation and tourism increases.

\subsection{From Dyadic to Triadic: Theoretical Background}

The dyadic model of signs, as formulated by Ferdinand de Saussure (1857-1913), is composed of two elements: the signifier and the signified. De Saussure's signifier is the form of the thing that enters through the senses while the signified is the idea of that thing that enters the mind. The underlying epistemology here is that we directly know ideas or interior perceptions only [24] and the link between the two elements is arbitrary [25]. From the outset, we observe a disjoint between the two elements that works well for linguistic purposes but not in the extra-linguistic realm [26].

Applying this model to a heritage building, the building's form (the signifier) is given meaning (the signified) by people arbitrarily or by convention. The instability of the link, which is crucial in determining the objective basis of the value of a given heritage building, becomes problematic. In other words, there is no firm ontological-thus, more stableconnection between the signifier and what it signifies outside of the mind. Thus, it all 
depends, in a Cartesian fashion, on the mind and on how it receives the form to attribute the signified. It is not surprising that despite being descended from ancient monuments, modern built-heritage is seldomly referred to as a sign. This may be because the dyadic model of signs is generally used more.

Besides the dyadic model, there is the triadic model of signs championed by Charles Sanders Peirce (1839-1914) [27]. Although a triadic model is conceptually more difficult to picture, it nevertheless seems to be closer to what happens in reality, at least with signs. As some authors $[27,28]$ note, the notion of signs being triadic is not something modern. In fact, these ideas can be found in documents from Aristotle's time to the Middle Ages, particularly the Tractatus de Signis of John Poinsot [29]. More recently, Metro Roland [26] applied this triadic model in analysing tourist places.

Among the three elements of this model, the first is the sign vehicle (or representamen in Peircian parlance), which is actually what we conventionally call the sign, like smoke that points to the presence of a flame. The next element is the object or the significate to which the sign refers or points, as smoke points to fire, which also causes the smoke in this case. Lastly, the interpretant (in Peirce) or understanding of the cognitive power (in Poinsot) is the sense that the sign makes in the mind of the observer, like the impressed idea of fire when one perceives the smoke [23,27]. In summary, a sign is defined as "that \{representamen\} which represents something \{object\} to a knowing power \{interpretant $\}$ " [29] Question 2.

Poinsot [29] points out that the proof of this extramental objective link/relation lies in the representative-ness of a particular sign for a specific object and not to others. Thus, the interpretation is not merely dictated by the person's mind without limit. For instance, a statue of Sun Yat Sen could point for someone to a particular man or some Asianlooking person or someone in long garbs or the father of a nation. Nevertheless, it will be unlikely that the statue is outright associated with a cat-unless the statue has been intentionally depicted/modified with catlike features. Despite the different background of the interpreter and the fact that the bust could be interpreted by someone to be another person of a different era or place, there is a specific range of objects it could point to. The more similar, for instance, the statue is to the features of the person being portrayed, the more this link is reinforced. Thus, some judgment of a good or better sign could be made. It is in the object or significate, "the object external to the semiotic process of representation, [which] compels the sign and offers resistance and the boundaries within which interpretation can take place" [26] p. 273. The fact that there exists this delimitation of a sign vehicle's relation to its significate makes it something autonomous from the human mind, i.e., extramental (It may be worth noting that this approach of Peirce shows that we know reality outside of our minds by means of concepts that he also refers to as signs [24]. Morris [30] also adopted something similar when he differentiated between the reference, the subject, and the sign. This link with reality makes the model more stable and suited for this study's framework). One discovers it (or some of them, if there are many) instead of simply inventing or thinking it up. This is important in order to establish the objective existence of the signifying relation between a building and a historic event, for instance. Logic begs to disagree and argues that the sign-and-significate relation is just arbitrary or merely a "pure construct", i.e., a social construction only.

The third element in the sign triangle, the sense of the significate impressed on the cognitive power, is needed to complete the epistemological loop. By our own intuition and experience, an organic subjective component to a knower that allows for different people to receive each sign differently (although not too differently either as it is restricted by the first two elements) cannot be denied. As mentioned above, a sign makes sense only when it represents the significate to some knowing power [29]. This, in fact, is an indispensable dimension - the thirdness in the mode of being of a sign in Peircian [24] terms. In our case, it is an old building acting as a sign vehicle pointing to some important historical event/s and impressing them onto the mind of the beholder (or interpretant or pathema). 
Among the three sign elements, this third element has a legitimate subjective nature. The range of impressions by different stakeholders or tourists or even experts in the field of a possible instance of built-heritage evidences this subjective nature. Neither could we assert that the differences have great disparity. Contradicting interpretations and the possibility of error [26] evidently exist without nullifying, and in some cases even strengthening, the arguments for the objective element of the triadic model. Needless to say, training, experience, background, affinity, and humble study, among other factors, which are also known as 'collateral experience' [24,26,31], play a role in how one discerns the meaning of the representamen.

In heritage parlance, technical terms such as "collective memory" (attributed to Halbwachs in the 1950s), "genius loci" [8], and "value responses" [32] allude to the tendency of people to understand and appreciate a place in a common way. While respecting the individuality of a group's members, this common way needs an intangible extramental reality-more than just the material realities_-as the basis for what the edifice impresses on its beholders. In this respect, the framework can also help us to understand the social value of a site.

\subsection{Squares as Built Heritage: Case Study Method}

In order to elucidate the incipient framework better, some squares of Macau's Historical Centre were chosen as a case study. The information about the sites was primarily obtained from the published literature, site visits (the last of which was in early 2020, right before borders were closed), and communication with Dr. Francisco Pinheiro. He was part of the team involved in the renovation of the latter two squares. The objective of this case study is to show that: (1) triadic semiotics play a more important and practical role in influencing heritage value than the material age and material features of an edifice or structure; and (2) it is possible to obtain an objective grading of the structure from this semiotic perspective. The reasons for using these squares are as follows:

1. The structures are relatively new compared with the inscribed monuments they surround. This providentially removes the age parameter of the built structures from the analysis.

2. Immediately preceding their present form and use, the sites were either used as a vehicular road, a parking space, or a less-frequented open space. This lessens or removes from our analysis some recent social attachments that people may strongly have had for them.

3. There are a number of very clear semiotic elements present on them.

4. An internationally recognised body has evaluated the sites.

The author chose three of the squares in the Historic Centre of Macau. These are: Leal Senado Square, Cathedral Square, and Lilau Square. See Figure 1 for the location of the squares relative to the monuments and to each other. Using these three sites, one may see how semiotic valorisation influences land use and vice versa.

\subsection{Leal Senado Square}

Leal Senado Square was designed by Francisco Caldeira Cabral in 1992 [33]. From a vehicular and parking space (see Figure 2), it was turned into a purely pedestrian open space (see Figure 3). The spacious square fronts the Senate, the political centre of the Portuguese colonial government in the past. Additionally located there is an inscribed 16th century monument, the Holy House of Mercy, a building used by a charitable institution. During the 1993 renovation, the floor of the square was tiled with cobblestone imported from Lisbon, following a wave pattern inspired by the 'Mar Largo' (Large Sea) project in Rossio Square, a popular downtown square in Lisbon [33]. Located at the centre of the square is a fountain, which contains symbolism of Portuguese maritime discoveries and expansions [33]. Evidence from a photo taken in the 1930s shows small wave patterns and a small well where the present armillary of the fountain is now placed [33]. 


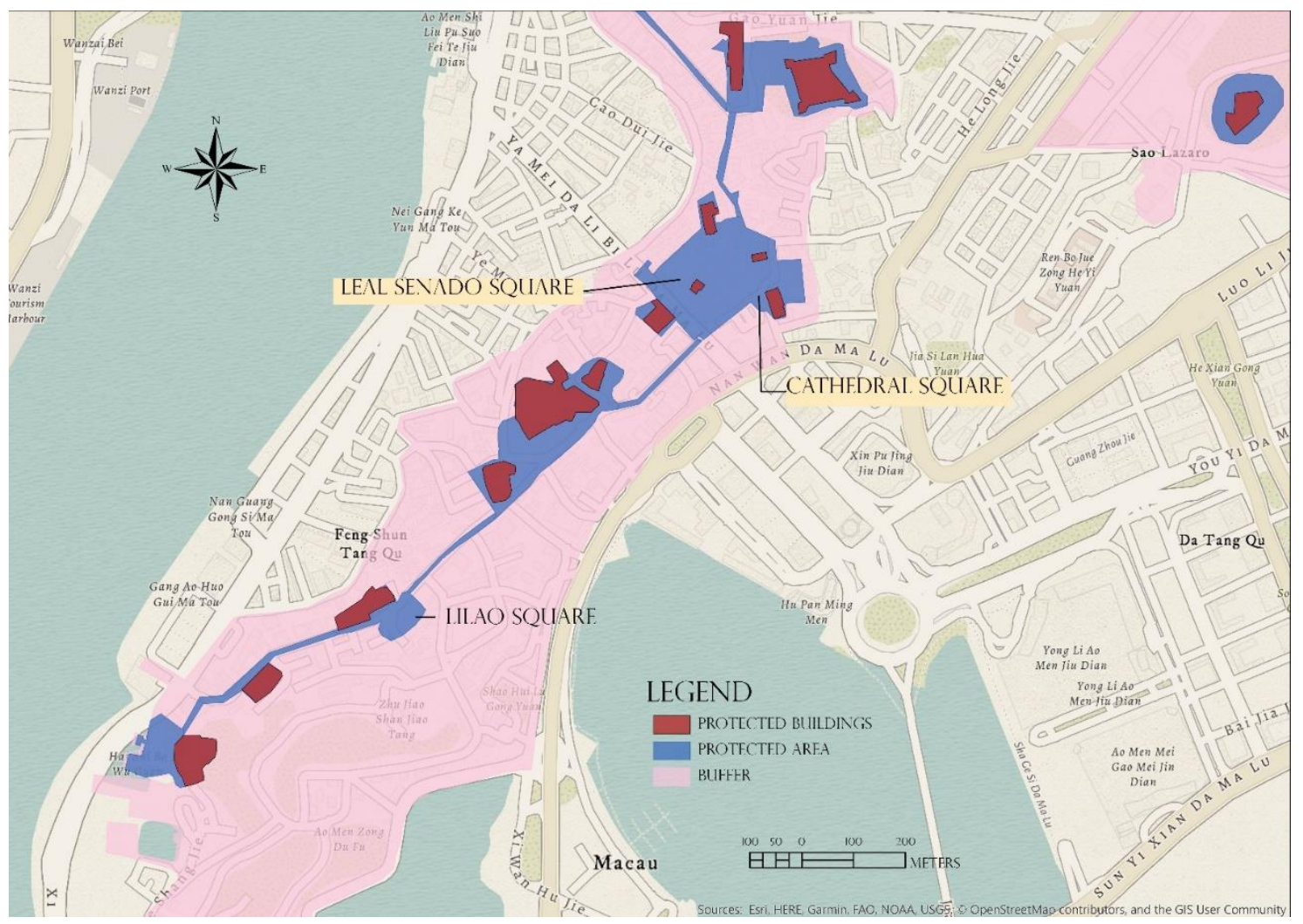

Figure 1. A map showing the location of the squares relative to each other. (drawn by the author based on Plan Document No. 2 in the nomination document [9]).

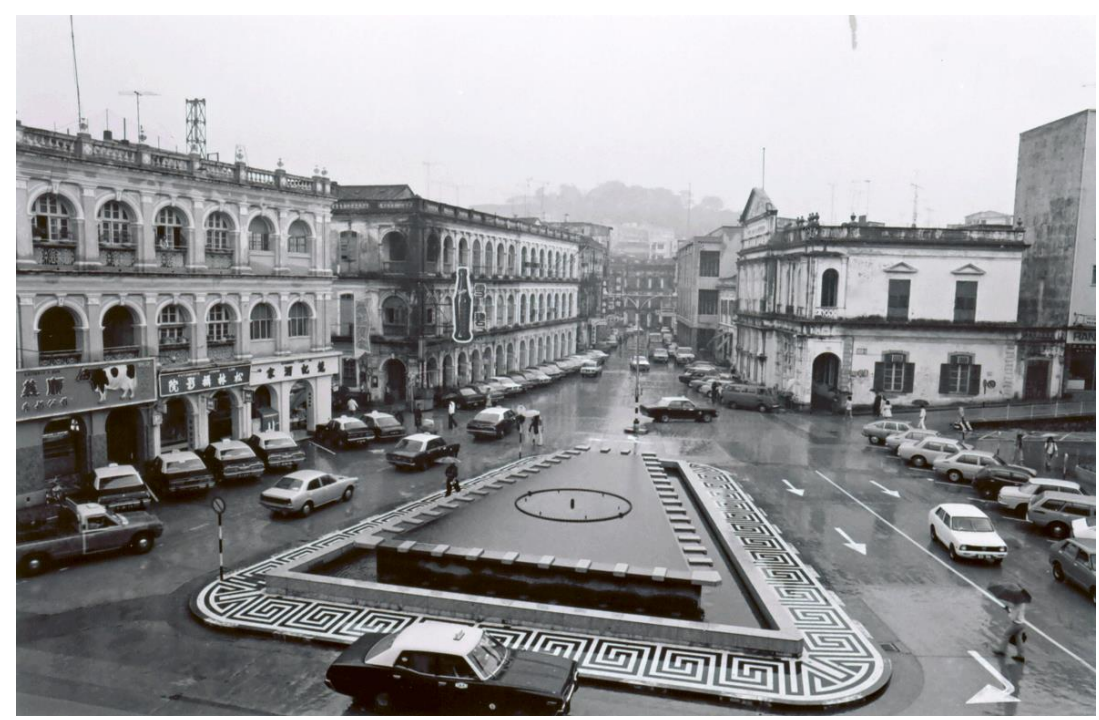

Figure 2. Leal Senado Square in the 1970s (image from a postcard by Lei Chiu Van). 


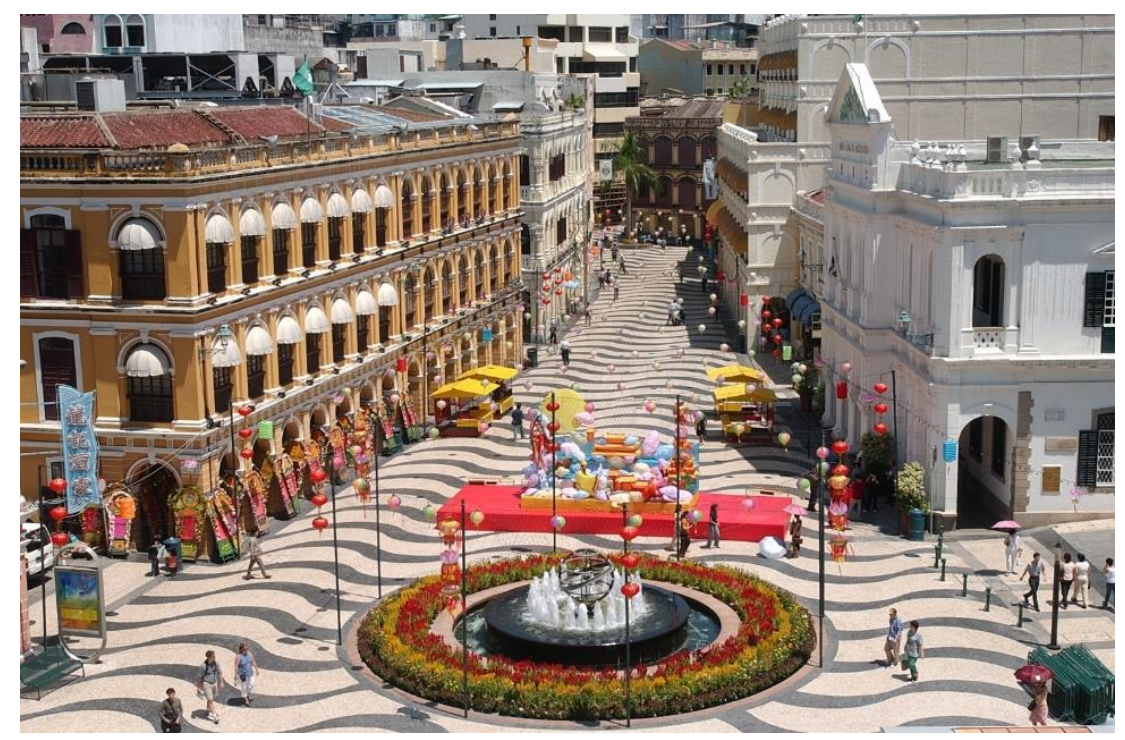

Figure 3. Leal Senado Square in 1993 (Courtesy of the then GCS, Social Communication Bureau).

\subsection{Cathedral Square}

In the past, the Cathedral Square was the heart of the gathering and processions of the Christian City. It is flanked by an inscribed monument-the Cathedral Church (which was rebuilt in 1850) - and other diocesan buildings reminiscing about the previous missionary role of Macau in Asia. Prior to the 2004 rehabilitation program, the square was a car park (see Figure 4).
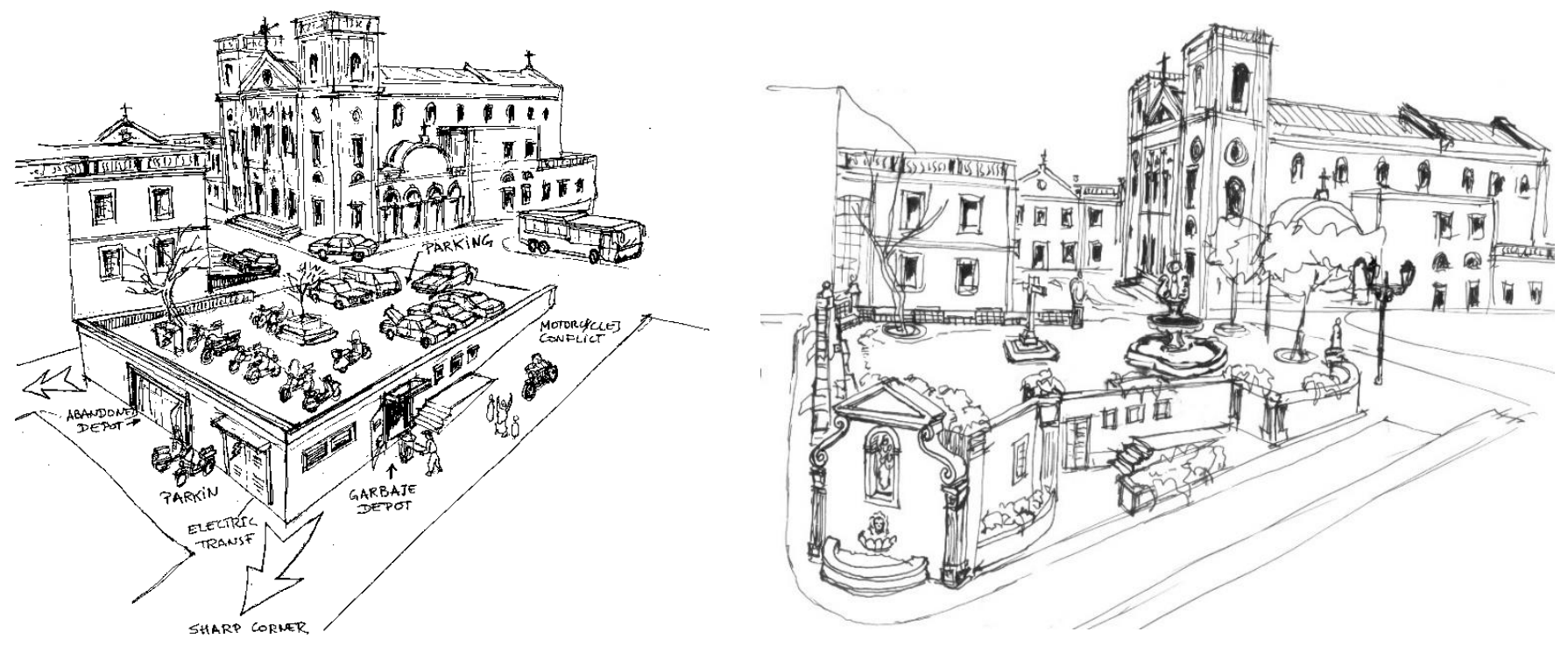

Figure 4. Cathedral Square before and after the renovation, drawn by Francisco Pinheiro.

Fountains and cobblestones were added during the renovation. These fountains contain images related to the historical meaning of the place, Cathedral Square, and Bishop Palace as the seat of the Catholic missionary authority in Asia, which reaches not only China, but also Japan and other countries in the region. Its floor is now tiled with cobblestones decorated with designs of stars, the sun, Alpha, and Omega. Very prominent in the square are the large Cross and a fountain with carp at the base. Therefore, the rehabilitation plan considered the historical meaning of the place as well as Portuguese and Chinese elements, such as good fengshui, to balance out the bad energies of some elements, such as sharp corners. Images of dolphins in the original design were turned to carp, and the image of the 
Virgin had some Buddhist features [34]. As another example, at the formerly sharp corner of Largo da Se now lies another fountain with a map of different prominent landmarks of Macau and figures of persons in its history (see Figure 5).

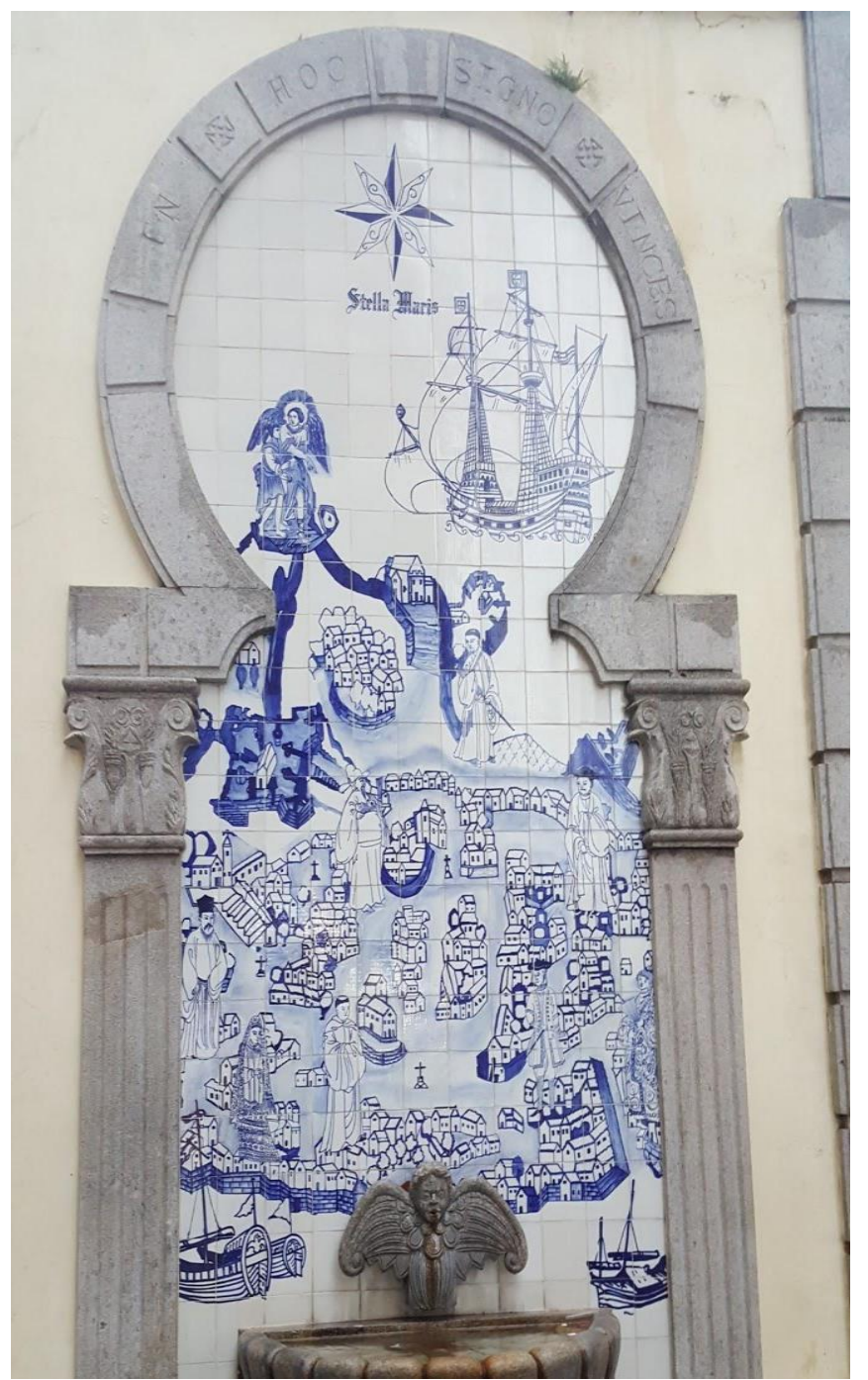

Figure 5. Fountain at the corner of Large da Se (by the author, 25 January 2020).

\subsection{Lilau Square}

Renovated in 2010, Lilau Square was an answer to the local population's criticism of the 1996 design of the square, in which modern design elements such as a granite rectangular wall with two faucets were supposed to signify the old Portuguese fountain and a Chinese well. Local people criticised this design because this fountain looked like a tomb from a cemetery (from a Chinese article in Macau Today, 16 April 2009). In 2010, this fountain was replaced with a traditional fountain with the face of a baby, replacing the old man's head that was there in the 1940s. A new colourful pavement (red and white) with an organic design, representing water from the fountain and the well, replaced the previous granite grid. In a survey done during the project's development, more than $80 \%$ of the enquiries preferred the traditional design to the abstract interpretation elaborated in the 1990s (as related by Dr. Francisco Pinheiro).

\section{Discussion: Sustainability in Delimitation}

In this section, the benefits of adapting the triadic model to built-heritage is discussed using a Coasian sustainability perspective, specifically the "third" Coase theorem (The 
numbering is not that essential. The first and second Coase Theorems were derived by George Stigler in his 1966 book The theory of price). This version of the theorem was discovered by Cheung [2] in the 1991 Nobel laureate Ronald Coase's 1959 paper [35] on the Federal Communication Commission. It states that "delimitation of rights is an essential prelude to market transactions" [35] p. 27. The ideas from this theorem have been applied in various environmental sustainability studies, including fisheries and fur [36,37]. The beauty of this theorem is it makes clear the need for the delimitation of some parameters in order to allow for some form of agreement to be reached with a lower transaction cost. This transaction cost may be in the negotiation between stakeholders or the monetary/time cost of discerning what is essential and is not. For instance, Wang and others [38] indicate a metaphysical duality in determining the role that the squares in front of the monuments play at the beginning of Macau's World Heritage application process.

Adapting this framework to heritage valuation, when built-heritage is epistemologically regarded as a triadic sign of the semiotic object in the past, then the range of interpretations could be limited to a more restricted range and even possibly be ranked. Where a more restricted range of interpretations is absent, one may even be suspicious about whether a place is really heritage. Pragmatically, this delimitation may allow for less contention and eventual grading of the place for sustainable conservation.

Before proceeding further with the discussion, it may be worth mentioning that the semiotic relation between the sign vehicle and its object is not strictly identical to the sign vehicle's own extant characteristics, design, function, etc., even if the object's qualities and sign-ness are simultaneously perceived by a cognitive power. Normally, the representative characteristics or qualities (e.g., a kind of similitude or affinity [24]) of a sign allows it to point to its object more vividly. A century-old church building (sign vehicle) may have its own qualities, dimensions, aesthetic merit, and current users but it simultaneously acts as a sign that points to something in the past (e.g., the ingenuity of its ancient makers, its former function, which has great impact on the history of the place, the past users of the building). These two levels of cognising a built structure are not exactly the same.

Looking at the case study, Leal Senado Square has its own aesthetic merits and functionality as an open space. However, from a heritage value perspective, its semiotic aspect is useful. For instance, the cobblestone flooring (representamen) alludes to something Western, i.e., Portuguese; however, its location being surrounded by nearby monument buildings strengthens the signifying capacity of the heritage buildings to its colonial Portuguese roots. Even the contrast between its former vehicular use and its current use as a pedestrian space now contributes to this semiotic effectiveness as a "praça" or "plaza" from the past.

This is not free from contention. Immediately before the squares were included in the protected area of the Historic Centre, there was some controversy about the authenticity of the rendition. The opposing party labeled the renovation of Cathedral Square as "fake old" and regarded it as not authentic. Authenticity from a critic's point of view implies that a more contemporary structure is more authentic (as related by Dr. Francisco Pinheiro). In the case of Lilau Square, the rehabilitation of the square in 2010 into what it is now was not regarded by the Committee as something against the heritage value. The methodology used for Lilau, approved earlier by the ICOMOS experts when they studied Leal Senado, involved the use of pavement patterns representing waves of water that flowed from the place of the existing fountain and the place of the memory of the well. Moreover, prior to the renovation, a survey was carried out to determine the local community's preference as shown in Figure 6. It appears that $89 \%$ of the public believed that the square's design ( 2 and B) should reflect the local history and culture, while $86 \%$ preferred to use a classic language to reinstall the fountain and well based on community memories in opposition to the minimalist solution (1 and A) (as related by Dr. Pinheiro in a lecture delivered in 2019). This may approximate an external manifestation of the interpretant of the square pointing to its past even if it is not exactly how it looked then. 

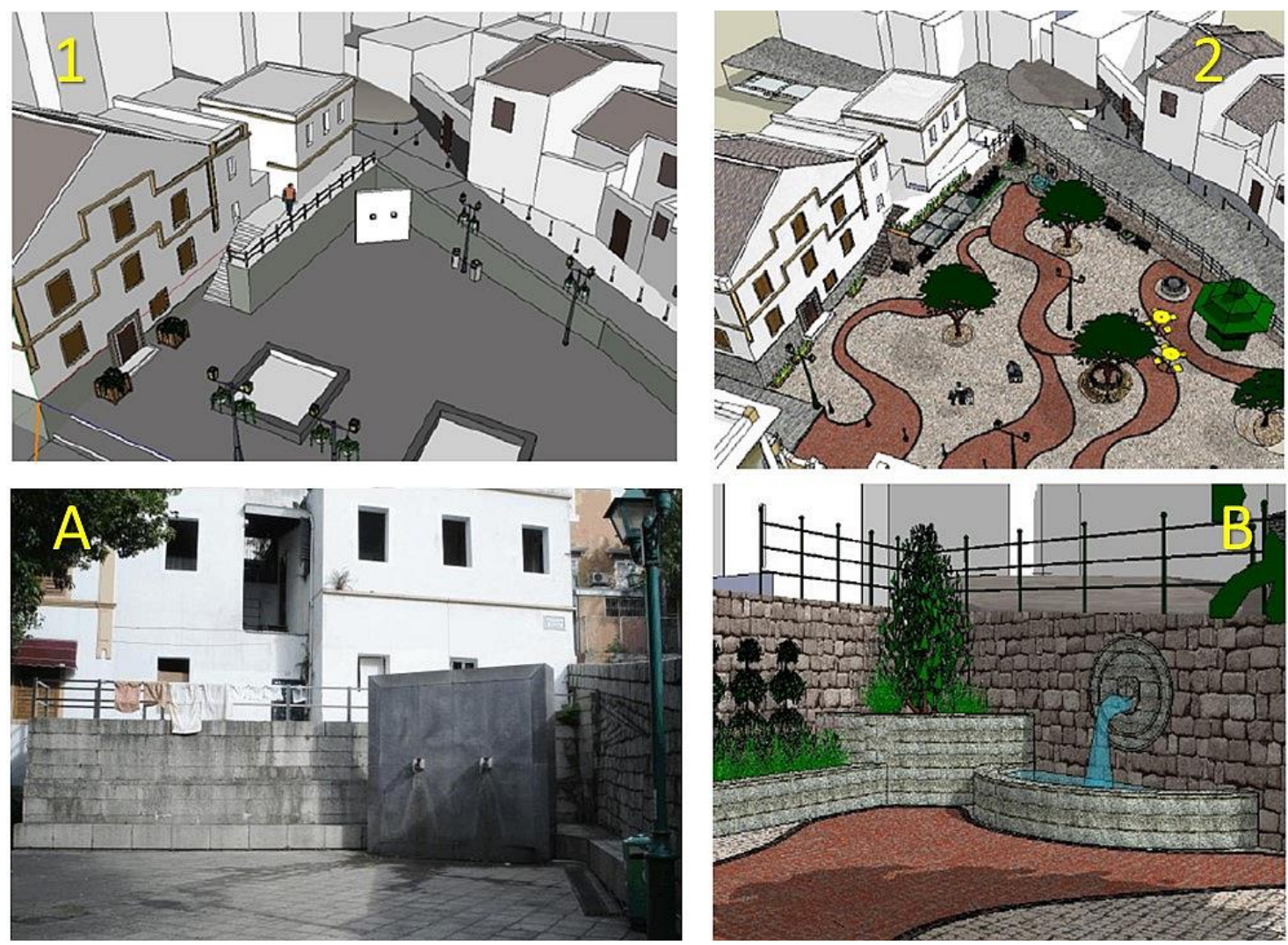

Figure 6. The images of Lilau Square before (plates $1 \& \mathbf{A}$ ) and after (plates $2 \& \mathbf{B}$ ) the renovation as shown to the respondents of the survey. (Courtesy of Francisco Pinheiro).

Another interesting point about this case is that the squares are new developments. Except, perhaps, for the land they are on, they are not strictly old compared with the surrounding inscribed buildings (monuments). The cobblestones used were, at the earliest, imported in the 1990s. This raises the issue of Theseus' ship paradox [6,19]. Less and less of the "old" materials of an edifice are left and are replaced by more and more "new" materials. In restoration projects, the "original" parts-despite remaining distinguishable from the added materials-slowly disappear and are supplemented with new materials. In this case, it can be seen that authenticity transcends the material portion of the built structure. Logically, the presence of the original material contributes significantly to the semiotic effectiveness of the built structure. However, to answer the question of how much should remain to still be heritage, it becomes more a question of the quality of the rendition more than the mere quantity of the original material. The triadic model's epistemological framework seems to cater to this analytical approach more appropriately.

On another note, we observe that the cognitive power (e.g., tourists and visitors) can also be aided by markers [39], regardless of whether they are on-site facilities such as plaques explaining the history of the place or off-site ones such as documents (brochures, flyers, guide maps), websites, or applications. These markers help to identify and expound on the sign structures-built-heritage-but they are not substitutes or replacements for them. The squares are also rich in Chinese and Portuguese semiotic elements to the point that they reinforce the inscribed structures surrounding them. The images of ships, shells, fountains, crosses, mandarin officials, scholars, and landmark sceneries, which surely were not etched on the pavement in the past, still help the cognitive powers to allude to the Chinese, Portuguese, and Christian roots of the place.

The empirical argument in this paper hinges on the fact that these squares were designated as protected areas in the World Heritage Listing despite their newness and the lack of strong prior social attachments of the community (as they were mostly vehicular 
spaces). It seems that what stands out in the squares is more their semiotic features, and it is surmised that they have been de facto treated as triadic signs by evaluators. The range of semiotic interpretations must have been narrow enough to allow for such an evaluation. In fact, when Macau's nomination to the World Heritage List shifted from including only specific monuments to a stretch of urban area including the squares [38], it somehow ratified the square's heritage role. Macau was inscribed on the basis of satisfying four out of six criteria for cultural sites [9]. It is evident that the squares contribute semiotically to the "unique testimony to the first and longest-lasting encounter between the West and China [9] p. 62" through the many instances of Portuguese-Chinese intermixing in its architecture and design. The author does not discount the fact that some may contest the authority of the committee; nevertheless, these experts' evaluation still has its merits and has been recognised internationally for a number of years now.

It is commonly agreed that it is difficult to put an exact number on the value of articles such as pieces of art or antiques-also known as cardinal measurement. Builtheritage is no exception. However, this is not the only way of taking measurements. At the margins, Ronald Coase and his colleague and friend Steven Cheung [2] do acknowledge that one item may have more value than another. Instead of naming an exact price, perhaps comparative value/rank can be a basis for measurement. This kind of ranking is referred to as ordinal measurement. In an experiment, Cheung [40] in 1975 asked five experts to value 10 jade items. Although the prices the experts gave were not the same, it is fascinating that they all ranked the items according to value in the same order.

Hekkert and Weiringen [41] obtained some similar findings on the agreement of experts' evaluation versus non-experts' evaluation with respect to the originality of the sample artworks used in the experiment. Although there was not much difference between the experts and the non-experts in other aspects, such as quality and expressiveness, experts were more consistent on the subject of originality. In a study of Prague's city brand with 59 experts, Matlovičová and others [42] found that local experts have less variance and more specificity compared with foreign ones.

It is precisely this consistency-albeit imperfect - that makes experts' opinion objective enough to be useful. In the triadic framework, the possibility of experts coinciding on a more limited range of interpretations would bring down the transaction cost significantly, allowing for an objectivist value to be agreed upon.

\section{Conclusions}

The common perception that heritage buildings signify subjectively, dependent on the person perceiving it at that moment, derives from the idea that what is signified depends on the mind (i.e., the background, education, and preferences of the person perceiving the object). Common experience seems to justify this way of thinking to a great extent. However, this mode falls short in explaining the objectivistic behaviour of these buildings that couple certain responses, such as the possibility - not without violence, at times-of getting a majority of people (experts or stakeholders) to agree on this or have an objective value-response [32] to a place.

This paper attempts to contribute to theorisation by identifying Peirce's triadic sign model with the nature of built-heritage. The relation of an edifice to what it points to is not just a hodgepodge of different cause-effect relations, similarity relations, or the identity of dyadic relations but a triadic sign relation. A sign is defined as "that which represents something to a knowing power" [29] Question 2-all three elements are needed to completely define what we experience as signs. In more practical terms, the framework gives an epistemological foundation for valuation activities; for instance, there are experiments identifying Prague's brand in terms of Peircian icons, indexes, and symbols [42] that already assume the triadic model. Many of these city icons (landmarks, famous persons, and events) have remained quite stable through the years in the minds of City Brand Index respondents [43]. Results from these types of experiments may help with land use and conservation decision-making. 
This study attempted to use World Heritage grading of the squares in the Historic Centre of Macau to show that the triadic sign-ness of the squares plays a dominant role in their heritage value. We saw in the previous section that the squares in Macau are relatively new compared with the inscribed monument buildings; in addition, they did not have a very strong social attachment in their previous use. Yet, the authoritative body has acknowledged their value as part of the entire fabric of the place.

In echoing Abercrombie's statement in the preamble about what is essential and what may be changed, this essential objectivist view may be compatible with different subjectivist impressions. However, looking at built-heritage in a dyadic mode leads to an epistemological objectivist-subjectivist dichotomy. In carrying out the complex assessments of and planning for a piece of property deemed to be heritage, this dichotomy may not be beneficial. This study, in a respectful response, argues that a more suitable epistemology for them would use the triadic sign model. While allowing for various impressions and interpretations of the built heritage sign vehicle, its semiotic object provides resistance to an endless number of interpretations in order to lower the transaction cost of discerning whether or not it is heritage. If an edifice's representative-ness is weak or the number of interpretations overly high, then it is doubtful that its heritage value will be high.

Funding: This research received no external funding.

Institutional Review Board Statement: Not applicable.

Informed Consent Statement: Not applicable.

Data Availability Statement: Not applicable.

Acknowledgments: The author thanks Francisco Pinheiro for his invaluable help and insights on this paper. He would also like to thank Lawrence Lai and the three anonymous referees for their encouraging and constructive comments and suggestions. All faults are the author's.

Conflicts of Interest: The authors declare no conflict of interest.

\section{References}

1. Abercrombie, P. Town and Country Planning, 2nd ed.; Oxford University Press: London, UK, 1945.

2. Cheung, S.N.S. The Transaction Costs Paradigm 1998 Presidential Address Western Economic Association. Econ. Inq. 1998, 36, 514-521.

3. Pereira-Roders, A.; Van Oers, R. Guidance on Heritage Impact Assessments. J. Cult. Herit. Manag. Sustain. Dev. 2012, 2, 104-114. [CrossRef]

4. Patiwael, P.R.; Groote, P.; Vanclay, F. Improving Heritage Impact Assessment: An Analytical Critique of the ICOMOS Guidelines. Int. J. Herit. Stud. 2019, 25, 333-347. [CrossRef]

5. Cheung, S.C. The Meanings of a Heritage Trail in Hong Kong. Ann. Tour. Res. 1999, 26, 570-588. [CrossRef]

6. Boccardi, G. Authenticity in the Heritage Context: A Reflection Beyond the Nara Document. Hist. Environ. Policy Pract. 2019, 10, 4-18. [CrossRef]

7. Petzet, M. Place, Memory, Meaning: Preserving Intangible Values in Monuments and Sites. In Proceedings of the ICOMOS 14th General Assembly and Scientific Symposium, Victoria Falls, Zimbabwe, 27-31 October 2003.

8. Petzet, M. Genius Loci-the Spirit of Monuments and Sites. In Proceedings of the ICOMOS 16th General Assembly and Scientific Symposium, QC, Canada, 30 September 2008.

9. ICOMOS. Nomination Document: The Historic Monuments of Macao. 2005. Available online: https://whc.unesco.org/uploads/ nominations /1110.pdf (accessed on 25 March 2021).

10. Agency for Cultural Affairs (Government of Japan); UNESCO; ICCROM; ICOMOS. The Nara Document on Authenticity. In Proceedings of the Nara Conference on Authenticity in Relation to the World Heritage Convention, Nara, Japan, 1-6 November 1993.

11. China ICOMOS. Principles for the Conservation of Heritage Sites in China; The Getty Conservation Institute: Los Angeles, CA, USA, 2004.

12. Australia ICOMOS Incorporated. The Burra Charter: The Australia ICOMOS Charter for Places of Cultural Significance; Australia, 2013. Available online: https:/ /australia.icomos.org/publications/burra-charter-practice-notes (accessed on 25 March 2021).

13. Agency for Cultural Affairs, Government of Japan. NARA + 20: On Heritage Practices, Cultural Values, and the Concept of Authenticity. 2014. Available online: http:/ / www.japan-icomos.org/pdf/nara20_final_eng.pdf (accessed on 25 March 2021).

14. Council of Europe. Framework Convention on the Value of Cultural Heritage for Society; Faro, Portugal, 2005. Available online: https:/ / www.coe.int/en/web/conventions/full-list/- / conventions/treaty/199 (accessed on 25 March 2021). 
15. English Heritage (Historic England). Conservation Principles: Policies and Guidance for the Sustainable Management of the Historic Environment. Drury, P., McPherson, A., Eds.; 2008. Available online: https://historicengland.org.uk/images-books/publications/ conservation-principles-sustainable-management-historic-environment/conservationprinciplespoliciesandguidanceapril0 8web (accessed on 25 March 2021).

16. UNESCO Intergovernmental Committee for the Protection of the World Cultural Natural Heritage, (2013 and 2015 and 2019$)$. The Operational Guidelines for the Implementation of the World Heritage Convention. Available online: http:/ / whc.unesco.org/ en/guidelines (accessed on 25 March 2021).

17. Zancheti, S.M.; Jokilehto, J. Values and Urban Conservation Planning: Some Reflections on Principles and Definitions. J. Archit. Conserv. 1997, 3, 37-51. [CrossRef]

18. Avrami, E.A.; Mason, R.; de la Torre, M. Report on Research. In Values and Heritage Conservation; The Getty Conservation Institute: Los Angeles, CA, USA, 2000; pp. 3-11.

19. Davies, S.N.G. Authenticity in the Conservation of Old Buildings; Unpublished Manuscript; University of Hong Kong: Hong Kong, China, 2014.

20. Throsby, D. Economic and Cultural Value in the Work of Creative Artists. In Values and Heritage Conservation; The Getty Conservation Institute: Los Angeles, CA, USA, 2000; pp. 26-31.

21. Arizpe, L. Cultural Heritage and Globalization. In Values and Heritage Conservation; The Getty Conservation Institute: Los Angeles, CA, USA, 2000; pp. 32-37.

22. De la Torre, M. Values and Heritage Conservation. Herit. Soc. 2013, 6, 155-166. [CrossRef]

23. Chandler, D. Semiotics: The Basics; Routledge: London, UK, 2002.

24. Peirce, C.S. The Essential Peirce: Selected Philosophical Writings; Originally 1893-1909; Houser, N., Kloesel, C.J.W., Eds.; Indiana University Press: Bloomington, IN, USA, 1998; Volume 2.

25. De Saussure, F. Nature of the Linguistic Sign; Originally 1916. In The Critical Tradition: Classic Texts and Contemporary Trends; Richter, D.H., Ed.; St. Martin's Press: Boston, MA, USA, 1998; pp. 832-835.

26. Metro-Roland, M. Interpreting Meaning: An Application of Peircean Semiotics to Tourism. Tour. Geogr. 2009, 11, 270-279. [CrossRef]

27. Deely, J. The Role of Thomas Aquinas in the Development of Semiotic Consciousness. Semiotica 2004, 2004, 75-139. [CrossRef]

28. Beuchot, M.; Deely, J. Common Sources for the Semiotic of Charles Peirce and John Poinsot. Rev. Metaphys. 1995, 48, 539-566.

29. Poinsot, J. Tractatus de Signis: The Semiotic of John Poinsot; Originally 1632; St Augustine's Press: South Bend, IN, USA, 2013.

30. Morris, C.W. Esthetics and the Theory of Signs. J. Unified Sci. (Erkenn.) 1939, 8, 131-150. [CrossRef]

31. Eco, U. Peirce's Notion of Interpretant. MLN 1976, 91, 1457-1472. [CrossRef]

32. Von Hildebrand, D. The Objectivity of Beauty. In Aesthetics; Crosby, J., Ed.; Hildebrand Project: Steubenville, OH, USA, 2016; Volume 1.

33. Pinheiro, F.V. Preserving Cultural Identity by Rehabilitation of Public Spaces: Case Study Analyses on the Historic Center of Macao, China, Unpublished Manuscript; Macau, China, 2016.

34. Pinheiro, F.V.; Cheong, C.K.; Chan, K.S. Rehabilitation of Squares in Macao's Historical Sites. In Modern Architecture in Asia Network MAAN Conference; University of Tokyo: Tokyo, Japan, 2005; pp. 1-5.

35. Coase, R.H. The Federal Communications Commission. J. Law Econ. 1959, 2, 1-40. [CrossRef]

36. Lai, L.W.; Chua, M.H.; Lorne, F.T. The Coase Theorem and Squatting on Crown Land and Water: A Hong Kong Comparative Study of the Differences between the State Allocation of Property Rights for Two Kinds of Squatters. Habitat Int. 2014, 44, 247-257. [CrossRef]

37. Demsetz, H. Toward a Theory of Property Rights. In Classic Papers in Natural Resource Economics; Springer: Berlin/Heidelberg, Germany, 1974; pp. 163-177.

38. Wang, Y.; Yamaguchi, K.; Kawasaki, M. Urban Revitalization in Highly Localized Squares: A Case Study of the Historic Centre of Macao. Urban. Des. Int. 2018, 23, 34-53. [CrossRef]

39. Culler, J. Semiotics of Tourism. Am. J. Semiot. 2007, 1, 127-140. [CrossRef]

40. Cheung, S.N.S. About King of Gems [Ye Tan Shi Di]. In Selections 1989; Arcadia Press Ltd.: Hong Kong, China, 2000; pp. 60-63, Originally in Chinese.

41. Hekkert, P.; Van Wieringen, P.C. Beauty in the Eye of Expert and Nonexpert Beholders: A Study in the Appraisal of Art. Am. J. Psychol. 1996, 389-407. [CrossRef]

42. Matlovičová, K.; Tirpáková, E.; Mocák, P. City brand image: Semiotic perspective a case study of Prague. Folia Geogr. 2019, 61, 120-142.

43. Anholt, S. The Anholt-GMI City Brands Index: How the World Sees the World's Cities. Place Branding 2006, 2, 18-31. [CrossRef] 